\title{
Molecular detection of QTL controlling plant height components in a doubled haploid barley population
}

\author{
X.F. Ren ${ }^{1,2}$, D.F. Sun ${ }^{1}$, W.B. Dong ${ }^{1}$, G.L. Sun ${ }^{1,2}$ and C.D. Li $^{3}$ \\ ${ }^{1}$ College of Plant Science and Technology, Huazhong Agricultural University, \\ Wuhan, China \\ ${ }^{2}$ Biology Department, Saint Mary’s University, Robie Street, Halifax, \\ NS, Canada \\ ${ }^{3}$ Department of Agriculture \& Food/Agricultural Research Western Australia, \\ South Perth, Australia \\ Corresponding authors: D.F. Sun / G.L. Sun \\ E-mail: sundongfa1@mail.hzau.edu.cn / genlou.sun@smu.ca
}

Genet. Mol. Res. 13 (2): 3089-3099 (2014)

Received February 5, 2013

Accepted July 3, 2013

Published April 17, 2014

DOI http://dx.doi.org/10.4238/2014.April.17.5

\begin{abstract}
Yield losses caused by lodging in barley can be partially controlled by reducing plant height. In order to understand dwarfing mechanisms and efficiently use new dwarf germplasms for a breeding program, it is important to identify QTL of plant height components. QTL analysis was performed for seven plant height component traits using a DH population of 122 lines derived from the cross of Huaai $11 \times$ Huadamai 6 . Composite interval mapping procedures detected 20 QTL, which were mapped onto chromosomes $2 \mathrm{H}, 3 \mathrm{H}, 5 \mathrm{H}, 6 \mathrm{H}$, and $7 \mathrm{H}$. Eleven QTL were detected in 3 years and four QTL were detected in 2 years. QTL controlling all seven plant height component traits were found near the dwarfing gene btwdl on chromosome $7 \mathrm{H}$. These QTL accounted for 27.19 to $59.73 \%$ of phenotypic variation in seven plant height component traits. Positive transgressive segregation was found for all traits. Some of the QTL identified in this study will be useful for
\end{abstract}


understanding the dwarfing mechanism and for developing new dwarf varieties using marker-assisted selection.

Key words: Internode length; Quantitative trait loci; Marker-assisted selection; Hordeum vulgare

\section{INTRODUCTION}

In barley breeding programs, grain yield is the most important trait to be considered. Lodging is a common problem in barley and in some situations can reduce the grain yield of barley by 28-65\% (Sisler and Olsen, 1951; Stanca et al., 1979; Jedel and Helm, 1991; Sameri et al., 2009). When a cereal crop suffers extensive lodging, fungal disease development on the spikes is increased, and the size and weight of grain and the efficiency of mechanical harvesting are drastically reduced (Stanca et al., 1979; Tar'an et al., 2003; Sameri et al., 2009). The tendency to lodge is a function of stem strength, so a dwarfing and semi-dwarfing plant minimizes the risk of lodging, as well as increasing the harvest index (Bezant et al., 1996; Hellewell et al., 2000). Therefore, it is essential to elucidate the genetic basis of plant height components to further increase yield.

In barley, plant height is an important agronomic trait. An appropriate plant height is a prerequisite for attaining the desired yield in barley-breeding programs. Genetic studies have indicated that plant height in barley is a complex trait controlled by both Mendelian genes and quantitative genes. More than 30 types of dwarfing or semi-dwarfing genes have been found, including ari, br, cud, ert, lzd, mnd, nld, sid, sld, dwf, uzu, denso, sdw1, bdwd1, etc. (Sears et al., 1981; Franckowiak, 1987; Franckowiak and Pecio, 1992; Zhang and Zhang, 2003; Ren et al., 2010). Among these dwarfing genes, $u z u$ has been widely used in barley breeding in China, Japan and Korea peninsula (Hoskins and Poehlman, 1971; Tsuchiya, 1976; Zhang, 1994, 2000; Saisho et al., 2004; Ren et al., 2010). $s d w 1$ has been verified in feed barley breeding in North America and Australia (Gymer, 1993; Hellewell et al., 2000; Jia et al., 2009; Ren et al., 2010). denso has been successfully used in European barley breeding (Zhang and Zhang, 2003; Jia et al., 2009; Ren et al., 2010). In addition to the semi-dwarfing and dwarfing genes, a number of quantitative trait loci (QTL) are also known to affect plant height in barley. QTL conferring plant height are reported to be located on all seven chromosomes (Backes et al., 1995; Kjaer et al., 1995; Hori et al., 2003; Pillen et al., 2003; Sameri et al., 2006; von Korff et al., 2006; Baghizadeh et al., 2007; Wang et al., 2010).

With the rapid development of molecular marker technology in barley, an increasing number of studies of qualitative or quantitative genes have been conducted in an attempt to dissect the genetic basis of plant height. Most of these studies have focused on final plant height without analyzing the influence of plant traits or the effect on the length of each internode in barley. Recently, a few studies on QTL analysis and the effect on culm length (CL) and internodes have been reported. Berry et al. (2006) reported that the lower internodes (particularly the second to the sixth) are of particular relevance to the lodging characteristics of a genotype. Sameri et al. (2006) reported that several QTL controlled CL, including a new QTL $(q C U L)$ for $\mathrm{CL}$ was detected on chromosome $7 \mathrm{HL}$, which controlled elongation, particularly that of the lower culm internodes in barley. Sameri et al. (2009) reported that QTL controlled plant height components and studied the inheritance of culm and culm internode lengths in 
barley. A QTL ( $q C U L)$ for reducing CL, which affected mainly the length of the third and fourth culm internodes, was also associated with reducing lodging (Sameri et al., 2009). A recent report indicated that the third internode position had an effect on the bending stress of the barley stem (Tavakoli et al., 2009). Therefore, characterizing the genetic relationships of plant height components at the QTL level will enhance our understanding of molecular mechanisms regulating plant height. This information will provide the theoretical basis for breeding programs designed to increase lodging resistance and to attain the desired yield levels.

In the present study, we performed a QTL analysis for seven plant height components using a DH population of 122 lines derived from the cross of Huaai 11 x Huadamai 6. Huaai 11 is a new source of dwarf discovered by our research group for broadening the genetic base of dwarfism. This dwarf trait was controlled by a recessive dwarfing gene $b t w d l$, and mapped on the long arm of chromosome 7H (Ren et al., 2010). To use this new germplasm Huaai 11 efficiently in barley-breeding programs, it is important to characterize the QTL controlling plant height components in this line. The objectives of the present study were: 1) to detect QTL for seven plant height components, and 2) to elucidate the genetic relationships between plant height components.

\section{MATERIAL AND METHODS}

\section{Plant materials and field experiments}

The genetic material used in this study was a population of $122 \mathrm{DH}$ lines derived from a cross between dwarfing barley cultivar Huaai 11 and a common feed barley cultivar Huadamai 6 using anther culture. The DH population lines and two parents were planted on the Experimental Farm of Huazhong Agricultural University, Wuhan, China. The field trials were conducted using a randomized complete block design with three replications in three years (2009-2010, 2010-2011 and 2011-2012). Each of the DH and parental lines were grown in three rows in a plot of $0.6 \times 2.0 \mathrm{~m}^{2}$. The length of rows was $2.0 \mathrm{~m}$, spacing between rows was $0.2 \mathrm{~m}$, and spacing of the plants was $0.15 \mathrm{~m}$. Seven traits were measured. Spike length (SL) was measured as "the length from the collar (base of spike) to the tip of spike (excluding awns)"; CL was measured as "the length from the ground to the collar"; the first internode length (IL1) was measured as "the length from the collar to the uppermost node"; and the second-fifth internode length (IL2-IL5) was measured as "the length downwards from the uppermost node". The mean of the twelve plants (measuring four central plants for each of three replicates) was calculated for each trait.

\section{SSR genotyping and statistical analysis}

The leaves from each DH line and parent were collected and frozen for DNA extraction according to Stein et al. (2001). Five hundred and thirty-six SSR markers on all seven barley chromosomes were used to screen polymorphism between the two parental lines. The PCR amplification procedure for SSR markers was performed as follows: an initial denaturation step of $4 \mathrm{~min}$ at $94^{\circ} \mathrm{C}$ followed by 30 cycles of denaturation for $40 \mathrm{~s}$ at $94^{\circ} \mathrm{C}$, annealing for 40 $\mathrm{s}$ at $50^{\circ}-65^{\circ} \mathrm{C}$, extension for $60 \mathrm{~s}$ at $72^{\circ} \mathrm{C}$, with a final extension for $8 \mathrm{~min}$ at $72^{\circ} \mathrm{C}$. A set of 153 polymorphic SSR markers were used to genotype the 122 individuals from the $\mathrm{DH}$ population. 
A linkage map was constructed using the MAPMAKER 3.0 software (Lander et al., 1987). The genetic distance (centimorgan, $\mathrm{cM}$ ) was derived using the Kosambi function (Liu and Meng, 2003). The most likely location of QTL and their genetic effects were initially detected by composite interval mapping using QTL Cartographer version 2.5 (Wang et al., 2007). A series of 1000 permutations were run to determine the experimental-wise significance level at $\mathrm{P}=0.05$ of the logarithm of the odds ratio ( $\mathrm{LOD} \geq 3$ ) for the trait (Churchill and Doerge, 1994). For the measurements and comparisons of variability among the seven plant height components, we calculated the standard deviation (SD). Analysis of variance (ANOVA) was carried out with the SAS software.

\section{RESULTS}

\section{Phenotypic variation}

Biologically, plant height in barley equals SL plus CL or SL plus all culm internode length above the ground. A desirable plant type is partially determined by combining these components. Mean values of plant height components for the parents Huaai 11 and Huadamai 6 and the DH lines are shown in Table 1. Huaai 11 was a six-row new source of dwarf that was controlled by a recessive dwarfing gene $b t w d l$, and Huadamai 6 was a two-row common feed barley cultivar. Large differences between the two parents were observed for all plant height components. Huadamai 6 showed higher values than did Huaai 11 for all seven plant height components across all years. DH lines showed significant differences for all plant height components measured in this experiment (Table 1). The wide range of variation in the traits investigated (Table 1) and the normal distributions of phenotypes (data not shown) indicated transgressive segregations, suggesting polygenic inheritance of the traits. Heritability estimates ranged from 61.76 to $88.29 \%$ (Table 1), indicating that it was possible to detect QTL for these traits by using a suitable linkage map. Analysis of variance of all plant height components also showed significant effects of year and genotype; significant interaction between genotype and year was only observed for CL, the IL4 and the IL5 (Table 2). As expected, all seven plant height components showed significantly positive correlation with each other (Table 3 ).

\begin{tabular}{|c|c|c|c|c|c|c|}
\hline \multirow[t]{2}{*}{ Traits } & \multicolumn{2}{|c|}{ Parental lines } & \multicolumn{3}{|c|}{ DH lines } & \multirow{2}{*}{$\begin{array}{c}\text { Heritability } \\
(\%)\end{array}$} \\
\hline & Huaai 11 & Huadamai 6 & Mean & SD & Range & \\
\hline $\mathrm{SL}$ & 4.85 & 9.87 & 6.49 & 1.81 & $3.44-11.39$ & 85.36 \\
\hline $\mathrm{CL}$ & 39.50 & 75.42 & 56.12 & 13.74 & $27.35-94.07$ & 73.21 \\
\hline IL1 & 16.78 & 31.94 & 22.99 & 4.51 & $11.20-34.68$ & 88.29 \\
\hline IL2 & 10.55 & 16.67 & 13.82 & 3.01 & $7.45-21.73$ & 76.16 \\
\hline IL3 & 6.87 & 11.01 & 8.68 & 2.63 & $3.47-15.99$ & 69.45 \\
\hline IL4 & 4.01 & 8.04 & 6.43 & 2.64 & $1.10-13.33$ & 64.58 \\
\hline IL5 & 1.06 & 4.91 & 2.91 & 2.11 & $0.00-11.65$ & 61.76 \\
\hline
\end{tabular}

$\mathrm{SL}=$ spike length; $\mathrm{CL}=$ culm length; IL1-IL5 = first to fifth internode length.

\section{Identification of QTL associated with different traits}

A set of 153 polymorphic SSR markers were used to genotype the 122 individuals 
Table 2. Analysis of variance on agronomic and quality traits in DH lines from Huaai 11 x Huadamai 6.

\begin{tabular}{lcccccrr}
\hline Source of variation & SL & CL & IL1 & IL2 & IL3 & IL4 & IL5 \\
\hline Year & $49.14^{* *}$ & $446.88^{* *}$ & $188.52^{* *}$ & $190.18^{* *}$ & $398.55^{* *}$ & $421.08^{* *}$ & $176.18^{* *}$ \\
Genotype & $692.59^{* *}$ & $1177.73^{* *}$ & $261.83^{* *}$ & $702.99^{* *}$ & $665.70^{* *}$ & $765.89^{* *}$ & $620.12^{* *}$ \\
Year x genotype & 0.75 & $4.57^{*}$ & 0.90 & 2.18 & 2.12 & $8.50^{* *}$ & $14.23^{* *}$ \\
\hline
\end{tabular}

*Significant at the $5 \%$ level. **Significant at the $1 \%$ level. For abbreviations, see legend to Table 1 .

\begin{tabular}{|c|c|c|c|c|c|c|}
\hline & $\mathrm{CL}$ & IL1 & IL2 & IL3 & IL4 & IL5 \\
\hline SL & $0.777^{* *}$ & $0.612 * *$ & $0.733^{* *}$ & $0.652 * *$ & $0.692 * *$ & $0.761 * *$ \\
\hline $\mathrm{CL}$ & & $0.837 * *$ & $0.916^{* *}$ & $0.902 * *$ & $0.889^{* *}$ & $0.882 * *$ \\
\hline IL1 & & & $0.759 * *$ & $0.589^{* *}$ & $0.580^{* *}$ & $0.610^{* *}$ \\
\hline IL2 & & & & $0.841^{* *}$ & $0.762 * *$ & $0.721^{* *}$ \\
\hline IL3 & & & & & $0.934 * *$ & $0.793 * *$ \\
\hline IL4 & & & & & & $0.885^{* *}$ \\
\hline
\end{tabular}

**Significant at the $1 \%$ level. For abbreviations, see legend to Table 1 .

from the DH population, and the genetic map spanned $1051.8 \mathrm{cM}$ with an average marker distance of $6.9 \mathrm{cM}$. QTL analyses for all seven plant height component traits were performed. A total of 20 QTL were mapped on five chromosomes on the basis of data from 3 years for seven plant height components (Table 4 and Figure 1). The LOD value for each QTL was given in Table 4. The QTL were mapped on chromosomes $2 \mathrm{H}, 3 \mathrm{H}, 5 \mathrm{H}, 6 \mathrm{H}$ and $7 \mathrm{H}$. Among them, seven QTL were found on the chromosome 7H, eleven QTL were detected in the 3 years, four QTL in 2 years and five QTL only in 1 year (Table 4 and Figure 1).

\section{Spike length}

Two significant QTL had an effect on SL in all 3 years. The QTL Qsl2-15, on chromosome $2 \mathrm{H}$, accounted for 5.46 to $8.60 \%$ of the phenotypic variation, with the effect of decrease in SL. The QTL Qsl7-7 on chromosome 7H showed a major effect on controlling this trait, and accounted for 47.24 to $53.68 \%$ of the phenotypic variation with the effect being a decrease in SL (Table 4).

\section{Culm length}

Four QTL, distributed on four chromosomes, were significantly associated with CL. All QTL showed the effect of shortening CL. Qcl7-7 on chromosome 7H was detected in all 3 years and accounted for 36.16 to $50.24 \%$ of the phenotypic variation. The $Q c l 3-13$ on chromosome $3 \mathrm{H}$ was detected in the 2 years, 2010 and 2011, and accounted for 5.51 to $6.80 \%$ of the phenotypic variation. Qcl6-15, located on chromosome 6H, and Qcl2-10, located on chromosome $2 \mathrm{H}$, both explained smaller phenotypic variation and were detected in 2010 and 2011, respectively (Table 4).

\section{First internode length (IL1)}

Three QTL were identified for the IL1. Two QTL, Qion7-4, located on chromosome 
Table 4. QTL, their locations and effects for the traits of plant height components in DH lines from Huaai 11 x Huadamai 6.

\begin{tabular}{|c|c|c|c|c|c|c|c|c|c|}
\hline Traits & Years & QTL & Marker & Chromosome & LOD & Position & Range (cM) & Heritability (\%) & Additive effect \\
\hline \multirow[t]{6}{*}{$\overline{\mathrm{SL}}$} & \multirow[t]{2}{*}{2009} & Qs12-15 & Bmag813 & $2 \mathrm{H}$ & 8.89 & 83.3 & $75.9-87.1$ & 8.60 & -0.43 \\
\hline & & Qs17-7 & Bmac167 & $7 \mathrm{H}$ & 31.96 & 47.5 & $26.4-68.8$ & 49.16 & -1.26 \\
\hline & \multirow[t]{2}{*}{2010} & Qs12-15 & Bmag813 & $2 \mathrm{H}$ & 5.32 & 83.3 & $75.9-87.1$ & 5.46 & -0.51 \\
\hline & & Qs17-7 & Bmac167 & $7 \mathrm{H}$ & 30.97 & 47.5 & $23.4-68.8$ & 53.68 & -1.49 \\
\hline & \multirow[t]{2}{*}{2011} & Qs12-15 & Bmag813 & $2 \mathrm{H}$ & 6.68 & 82.9 & $75.9-87.1$ & 7.78 & -0.53 \\
\hline & & Qs17-7 & Bmac167 & $7 \mathrm{H}$ & 27.67 & 47.5 & $25.4-68.8$ & 47.24 & -1.41 \\
\hline \multirow[t]{7}{*}{$\mathrm{CL}$} & 2009 & Qcl7-7 & Bmac167 & $7 \mathrm{H}$ & 28.35 & 47.5 & $20.4-68.8$ & 50.24 & -8.03 \\
\hline & \multirow[t]{3}{*}{2010} & Qcl3-13 & Bmag13 & $3 \mathrm{H}$ & 7.15 & 98.9 & $90.7-115.9$ & 6.80 & -2.75 \\
\hline & & Qcl6-15 & Bmag 163 & $6 \mathrm{H}$ & 3.88 & 64.9 & $51.9-74.9$ & 3.49 & -1.88 \\
\hline & & Qcl7-7 & Bmac167 & $7 \mathrm{H}$ & 26.13 & 47.5 & $20.4-68.8$ & 36.16 & -7.02 \\
\hline & \multirow[t]{3}{*}{2011} & Qc12-10 & Bmag829 & $2 \mathrm{H}$ & 4.08 & 76.1 & $75.9-86.7$ & 3.06 & -2.22 \\
\hline & & Qt13-13 & Bmag13 & $3 \mathrm{H}$ & 7.43 & 98.9 & $89.7-110.9$ & 5.51 & -3.03 \\
\hline & & Qcl7-7 & Bmac167 & $7 \mathrm{H}$ & 32.18 & 47.5 & $20.4-68.8$ & 39.76 & -9.10 \\
\hline \multirow[t]{8}{*}{ IL1 } & \multirow[t]{3}{*}{2009} & Qion3-9 & Bmag129 & $3 \mathrm{H}$ & 3.02 & 56.3 & $53.7-73.7$ & 4.41 & 0.89 \\
\hline & & Qion6-15 & Bmag 163 & $6 \mathrm{H}$ & 3.81 & 65.9 & $47.8-75.9$ & 9.50 & -1.27 \\
\hline & & Qion7-4 & Bmag900 & $7 \mathrm{H}$ & 10.35 & 35.4 & $25.4-68.8$ & 31.34 & -2.37 \\
\hline & \multirow[t]{2}{*}{2010} & Qion6-15 & Bmag 163 & $6 \mathrm{H}$ & 5.58 & 68.9 & $47.8-75.9$ & 10.88 & -1.04 \\
\hline & & Qion7-4 & Bmag900 & $7 \mathrm{H}$ & 9.13 & 35.4 & $25.4-68.8$ & 27.19 & -1.63 \\
\hline & \multirow[t]{3}{*}{2011} & Qion3-9 & Bmag129 & $3 \mathrm{H}$ & 4.50 & 56.3 & $53.7-78.2$ & 8.59 & 1.05 \\
\hline & & Qion6-15 & Bmag 163 & $6 \mathrm{H}$ & 4.92 & 65.9 & $47.8-75.9$ & 10.20 & -1.12 \\
\hline & & Qion7-4 & Bmag900 & $7 \mathrm{H}$ & 12.10 & 39.4 & $25.4-68.8$ & 28.32 & -1.94 \\
\hline \multirow{6}{*}{ IL2 } & 2009 & Qitw7-7 & Bmac167 & $7 \mathrm{H}$ & 21.84 & 47.5 & $25.4-68.8$ & 33.75 & -1.95 \\
\hline & \multirow{2}{*}{2010} & Qitw3-13 & Bmag13 & $3 \mathrm{H}$ & 4.37 & 98.9 & $93.2-113.4$ & 3.73 & -0.48 \\
\hline & & Qitw7-7 & Bmac167 & $7 \mathrm{H}$ & 28.08 & 47.5 & $25.4-68.8$ & 39.28 & -1.72 \\
\hline & \multirow[t]{3}{*}{2011} & Qitw3-13 & Bmag 13 & $3 \mathrm{H}$ & 12.79 & 99.9 & $84.7-115.9$ & 12.19 & -1.00 \\
\hline & & Qitw5-10 & HVLEU & $5 \mathrm{H}$ & 6.48 & 32.1 & $23.1-34.4$ & 5.33 & 0.64 \\
\hline & & Qitw7-7 & Bmac167 & $7 \mathrm{H}$ & 33.33 & 47.5 & $20.4-68.8$ & 46.53 & -1.88 \\
\hline \multirow[t]{7}{*}{ IL3 } & \multirow[t]{2}{*}{2009} & Qith3-13 & Bmag13 & $3 \mathrm{H}$ & 3.16 & 98.7 & $85.7-108.9$ & 3.54 & -0.38 \\
\hline & & Qith7-7 & Bmac167 & $7 \mathrm{H}$ & 26.96 & 48.5 & $20.4-68.8$ & 59.46 & -1.49 \\
\hline & \multirow[t]{3}{*}{2010} & Qith3-13 & Bmag13 & $3 \mathrm{H}$ & 12.97 & 101.9 & $86.4-115.9$ & 15.75 & -0.75 \\
\hline & & Qith6-2 & Bmag500 & $6 \mathrm{H}$ & 3.84 & 26.1 & $24.9-39.6$ & 3.57 & 0.35 \\
\hline & & Qith7-7 & Bmac167 & $7 \mathrm{H}$ & 30.16 & 47.5 & $20.4-68.8$ & 49.39 & -1.27 \\
\hline & \multirow[t]{2}{*}{2011} & Qith3-13 & Bmag13 & $3 \mathrm{H}$ & 15.65 & 99.7 & $85.7-115.9$ & 17.36 & -0.98 \\
\hline & & Qith7-7 & Bmac167 & $7 \mathrm{H}$ & 33.43 & 47.5 & $20.4-68.8$ & 53.40 & -1.64 \\
\hline \multirow{6}{*}{ IL4 } & \multirow[t]{2}{*}{2009} & Qifo3-14 & Bmag877 & $3 \mathrm{H}$ & 3.26 & 114.9 & $104.7-125.9$ & 4.13 & -0.39 \\
\hline & & Qifo7-7 & Bmac167 & $7 \mathrm{H}$ & 22.37 & 47.5 & 20.4-68.8 & 47.11 & -1.34 \\
\hline & \multirow[t]{2}{*}{2010} & Qifo3-14 & Bmag877 & $3 \mathrm{H}$ & 10.88 & 108.9 & $95.7-125.9$ & 14.46 & -0.73 \\
\hline & & Qifo7-7 & Bmac167 & $7 \mathrm{H}$ & 27.79 & 47.5 & $20.4-68.8$ & 50.08 & -1.32 \\
\hline & 2011 & Qifo3-14 & Bmag877 & $3 \mathrm{H}$ & 6.4 & 106.7 & $95.7-118.7$ & 7.40 & -0.65 \\
\hline & & Qifo7-7 & Bmac167 & $7 \mathrm{H}$ & 33.50 & 47.5 & $20.4-68.8$ & 59.73 & -1.80 \\
\hline IL5 & 2009 & Qifi7-7 & Bmac167 & $7 \mathrm{H}$ & 20.06 & 47.5 & $20.4-68.8$ & 47.36 & -1.12 \\
\hline & 2010 & Qifi2-10 & Bmag829 & $2 \mathrm{H}$ & 6.09 & 76.1 & $75.9-86.7$ & 7.02 & -0.44 \\
\hline & & Qifi5-10 & HVLEU & $5 \mathrm{H}$ & 3.47 & 32.1 & $22.7-34.4$ & 3.86 & 0.32 \\
\hline & & Qifi7-7 & Bmac167 & $7 \mathrm{H}$ & 22.60 & 48.5 & $20.4-68.8$ & 52.20 & -1.13 \\
\hline & 2011 & Qifi2-10 & Bmag829 & $2 \mathrm{H}$ & 5.02 & 76.1 & $75.9-86.7$ & 5.91 & -0.57 \\
\hline & & Qifi7-7 & Bmac167 & $7 \mathrm{H}$ & 28.70 & 47.5 & $20.4-68.8$ & 55.70 & -1.68 \\
\hline
\end{tabular}

For abbreviations, see legend to Table 1.

7H, and Qion6-15, located on chromosome 6H, were detected in the 3 years, and both had the effect of decreasing the IL1 and explained 27.19 to $31.34 \%$ and 9.5 to $10.88 \%$ of the phenotypic variation, respectively. Qion3-13, located on chromosomes $3 \mathrm{H}$, was detected in 2 years, and this QTL had the effect of increasing the IL1 and explained 4.11 and $8.59 \%$ of the phenotypic variation in 2009 and 2011, respectively (Table 4).

\section{Second internode length (IL2)}

Three QTL were detected for the IL2. Qitw7-7, on chromosome 7H, was detected in all 
3 years and accounted for 33.75 to $46.53 \%$ of the phenotypic variation. Qitw3-13, on chromosomes $3 \mathrm{H}$, was identified for the IL2 in 2 years, and explained 3.73 and $12.19 \%$ of the phenotypic variation in 2010 and 2011, respectively. These two QTL had the effect of decreasing the IL2. However, Qitw5-10, located on chromosome 5H, had the effect of increasing the IL2. It was only detected in 2011 and explained $5.33 \%$ of the phenotypic variation (Table 4).
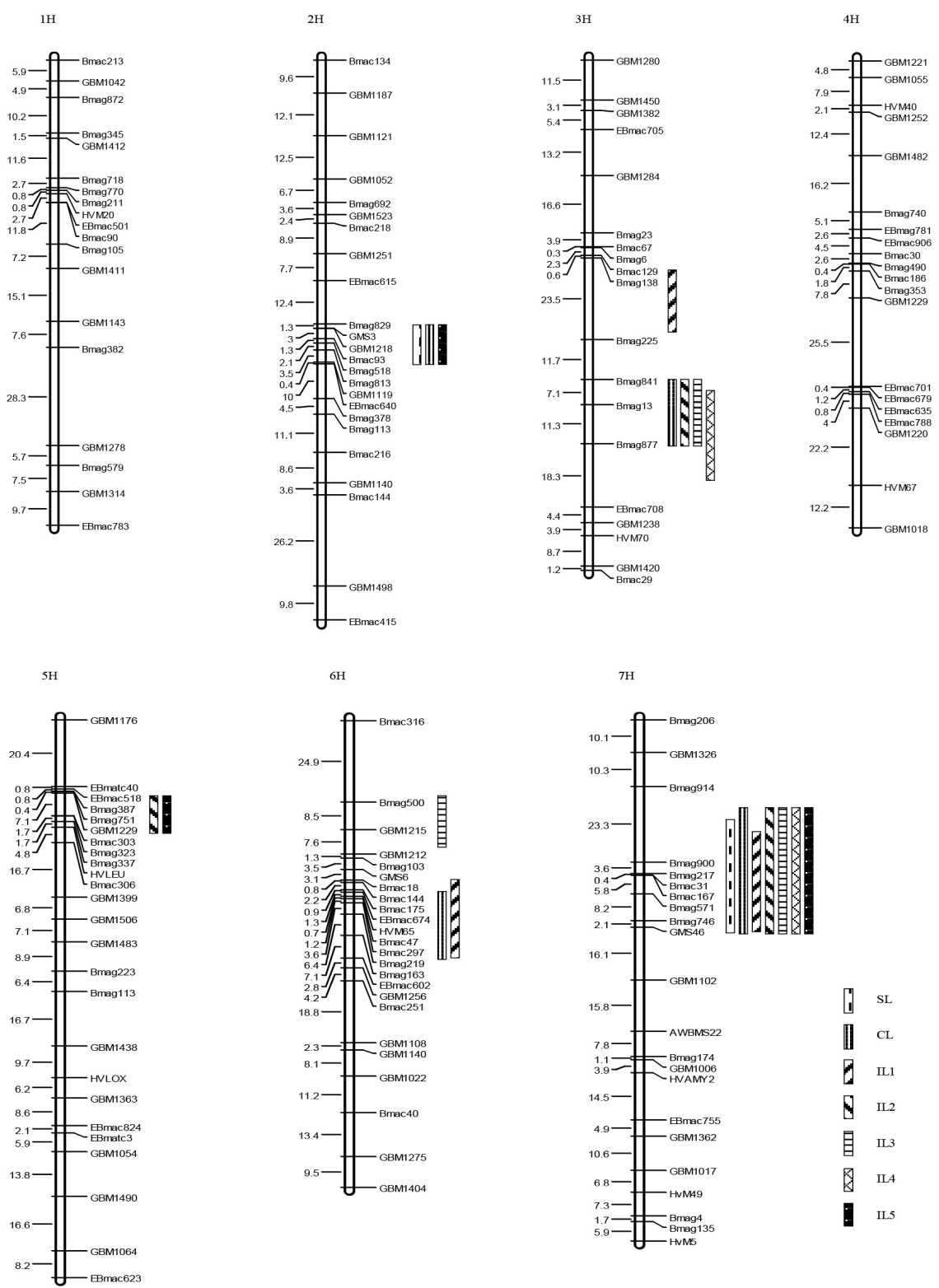

Figure 1. Map locations of 20 QTL of plant height component traits for the Huaai 11 x Huadamai 6 DH population. For abbreviations, see legend to Table 1. 


\section{Third internode length (IL3)}

Three QTL were detected for the IL3. Two QTL, Qith3-13, located on chromosome 3H, and Qith 7-7, located on chromosome 7H, were detected in the 3 years, and both had the effect of decreasing the IL3 and explained 3.54 to $17.36 \%$ and 49.39 to $59.46 \%$ of the phenotypic variation, respectively. Qith6-2 was located on chromosome $6 \mathrm{H}$ and had the effect of increasing the IL3. It was only detected in 2010 and explained $3.57 \%$ of the phenotypic variation (Table 4).

\section{Fourth internode length (IL4)}

Two QTL were identified for the IL4 in all 3 years. The QTL Qifo3-14, on chromosome $3 \mathrm{H}$, accounted for 4.13 to $14.46 \%$ of the phenotypic variation with the effect of decreasing the IL4. The QTL Qifo7-7, on chromosome 7H, showed a major effect of controlling the IL4, and accounted for 47.11 to $559.73 \%$ of the phenotypic variation, with the effect of decreasing the IL4 (Table 4).

\section{Fifth internode length (IL5)}

Three QTL were identified for the IL5. Qifi7-7, on chromosome 7H, was detected in all 3 years and accounted for 47.36 to $55.70 \%$ of the phenotypic variation, with the effect of shortening the fifth internode. Qifi2-10, located on chromosome $2 \mathrm{H}$, was detected in 2 years; it had the effect of decreasing the IL5 and explained 7.02 and 5.91\% of the phenotypic variation in 2010 and 2011, respectively. Qifi5-10, on chromosome 5H, was only detected in 2010 and accounted for $3.84 \%$ of the phenotypic variation, with the effect of increasing the IL5 (Table 4).

\section{DISCUSSION}

The utilization of dwarfing genes in barley-breeding programs has greatly increased barley yields, particularly in Asia and Europe (Yu et al., 2010). Plant height consists of CL and SL. QTL analysis is a useful approach to discover and dissect complex traits and to identify favorable alleles in diverse germplasm (Paterson et al., 1988). In the present study, we detected 20 QTL for seven plant height components using a DH population derived from a cross between a dwarfing barley cultivar Huaai 11 and a common feed barley cultivar Huadamai 6, in combination with composite interval mapping (CIM).

\section{QTL for plant height components}

Of the 7 plant height components studied here, the QTL for SL was previously widely reported and detected on all seven chromosomes in barley (Hori et al., 2003; Li et al., 2005; Sameri et al., 2006; Baghizadeh et al., 2007; Wang et al., 2010). In our study, two significant QTL with effect on SL in all 3 years were found. Examining the $2 \mathrm{H}$ and $7 \mathrm{H}$ linkage maps of Varshney et al. (2007) revealed that $Q s l 2-15$ is close to the centromere of the 2HL, and is different from those QTL on chromosomes $2 \mathrm{H}$ previously reported (Hori et al., 2003; Li et al., 2005; Sameri et al., 2006; Wang et al., 2010). Qsl7-7 is likely the same as Qel7.1 on chromo- 
some 7H previously reported (Li et al., 2005). Four QTL were significantly associated with CL. The Qcl7-7 was detected in all 3 years and Qcl3-13 was detected in 2 years. Two QTL, Qcl2-10 and Qcl6-15, were only detected in 1 year, with minor effect. QTL for CL were found on chromosomes 2HL, 3HL, 4HL, 5HL, 7HS, and 7HL (Sameri et al., 2006, 2009). Sameri et al. $(2006,2009)$ reported that QTL for CL on chromosomes $2 \mathrm{HL}, 3 \mathrm{HL}, 7 \mathrm{HS}$, and 7HL were linked with the marker (or gene) MWG801 (vrs 1), e06m30.10.1 (uzu), cMWG704 (dps1) and ABG608 ( $q C U L . a k-7 H)$, respectively. Examining the $2 \mathrm{H}, 3 \mathrm{H}$ and $7 \mathrm{H}$ linkage maps revealed that $Q c l 2-10, Q c l 3-13$ and Qcl7-7 are different from those QTL on chromosomes 2HL, 3HL, $7 \mathrm{HS}$, and 7HL reported by Sameri et al. $(2006,2009)$. No QTL for CL on chromosome $6 \mathrm{H}$ had been previously reported. Qcl6-15 was a newly identified QTL for CL on chromosome $6 \mathrm{H}$.

Fourteen QTL were detected for the internode length (IL1-IL5) on chromosomes 2H, $3 \mathrm{H}, 5 \mathrm{H}, 6 \mathrm{H}$, and $7 \mathrm{H}$. Eight QTL were detected in all 3 years, three QTL were detected in 2 years, and three QTL were detected in 1 year. QTL conferring internode length are reported to be linked with the genes vrsl (2HL), Ppd-Hl (2HS), uzu (3HL), sghl (4HL), Ema5 (5HL), sgh2 (5HL), qCUL.ak-7H (7HL) and $d s p 1$ (7HS) in barley (Sameri et al., 2006, 2009). Examining the $2 \mathrm{H}, 3 \mathrm{H}, 5 \mathrm{H}, 6 \mathrm{H}$, and $7 \mathrm{H}$ linkage maps of Varshney et al. (2007) and GrainGenes2.0 (http://wheat.pw.usda.gov) revealed that the location of Qion3-9 is close to the gene $u z u$ on chromosome 3HL, and thirteen QTL for the internode length are different from those QTL reported by Sameri et al. (2006, 2009). In our study, all seven plant height components showed a highly significant positive correlation with each other (Table 3 ). Therefore, they all play an important role in determining plant height components.

\section{Relationship of the btwd1 gene with plant height components}

The newly dwarfing germplasm Huaai 11 consisted of desirable agronomic traits such as shortened stature and early maturity (Ren et al., 2010). The gene btwdl controlling plant height in the Huaai 11 is non-allelic with the genes $b r, u z u, s d w l$, and denso (Ren et al., 2010). Conditional QTL mapping analysis provides an efficient tool to reveal relationships between plant height and plant height components. In this study, the strong-effect QTL of all seven plant height components were found near the dwarfing gene btwdl on chromosome $7 \mathrm{H}$. The QTL for seven plant height components on chromosome $7 \mathrm{H}$ accounted for 27.19 to $59.73 \%$ of phenotypic variation and with the effect of decreasing plant height. This result indicated that there is a special relationship between the gene $b t w d l$ and seven plant height components and that the gene btwdl controlled the entire plant height by controlling each plant height component studied here. Because some DH lines did not have the sixth internode, we only examined the IL1 to the IL5. The gene btwdl had a significant effect on the seven plant height components. Its effect on the third and IL4 was greatest, and on the IL1 the effect was smallest among the seven plant height components. This is the same as where the QTL for reducing CL $(q C U L)$ affected mainly the length of the third and fourth culm internodes in barley recombinant inbred lines reported by Sameri et al. (2009).

At the same time, we found that the gene btwdl in the Huaai 11 produced pleiotropic effects on improving other agronomic traits such as yield components. Minimizing the elongation of the lower internodes is an important strategy for increasing lodging tolerance (Yamamoto et al., 2001). In this study, the effect of the gene btwdl on internode length was IL3 $>$ IL4 $>$ IL 5 $>$ IL2 $>$ IL1, and it had a significant effect on lodging tolerance. Therefore, un- 
derstanding the genetic basis of internode length, especially for that of basal internodes, is of great importance when breeding barley cultivars with satisfactory levels of lodging resistance.

In summary, QTL analysis was performed for seven plant height components using a DH population of 122 lines derived from the cross of Huaai 11 x Huadamai 6 in this study. Seven traits were measured in the DH population in the 3 years. A total of 20 QTL were identified and explained 3.06 to $59.73 \%$ of phenotypic variation. Seven QTL on chromosome $7 \mathrm{H}$ were detected in the 3 years. The gene btwdl controlling plant height in the Huaai 11 plays an important role and has a significant effect on the seven plant height components. Some QTL identified in this study will be of great value for understanding the dwarfing mechanism and the genetic basis of plant height, and for developing new dwarf varieties using marker-assisted selection.

\section{ACKNOWLEDGMENTS}

Research supported by the National Natural Science Foundation of China (\#31301310 and \#31228017) and the Earmarked Fund for China Agriculture Research System (CARS-5).

\section{REFERENCES}

Backes G, Graner A, Foroughi-Wehr B and Fischbeck G (1995). Localization of quantitative trait loci (QTL) for agronomic important characters by the use of a RFLP map in barley (Hordeum vulgare L.). Theor. Appl. Genet. 90: 294-302.

Baghizadeh A, Taleei AR and Naghavi MR (2007). QTL analysis for some agronomic traits in barley (Hordeum vulgare L.). Int. J. Agric. Biol. 9: 372-374.

Berry PM, Sterling M and Mooney SJ (2006). Development of a model of lodging for barley. J. Agron. Crop. Sci. 192: 151-158.

Bezant J, Laurie DA, Pratchett N and Chojecki J (1996). Marker regression mapping of QTLs controlling flowering time and plant height in a spring barley (Hordeum vulgare L.) cross. Heredity 77: 64-73.

Churchill GA and Doerge RW (1994). Empirical threshold values for quantitative trait mapping. Genetics 138: 963-971.

Franckowiak JD (1987). Coordinator's report on the semi-dwarf barley collection. Barley Genet. Newslett. 17: 114-115.

Franckowiak JD and Pecio A (1992). Coordinator's report: Semi-dwarf gene: A listing of genetic stocks. Barley Genet. Newslett. 21: 116-127.

Gymer PT (1993). An attempt to locate the sdw gene for prostrate growth habit or the perils and pitfalls of classical genetics. Barley Genet. Newslett. 22: 19-22.

Hellewell KB, Rasmusson DC and Meagher MG (2000). Enhancing yield of semidwarf barley. Crop Sci. 40: 352-358.

Hori K, Kobayashi T, Shimizu A, Sato K, et al. (2003). Efficient construction of high-density linkage map and its application to QTL analysis in barley. Theor. Appl. Genet. 107: 806-813.

Hoskins PH and Poehlman JM (1971). Pleiotropic effects of uzu and spike-density genes in a barley cross. J. Hered. 62: 153-156.

Jedel PE and Helm JH (1991). Lodging effects on a semidwarf and two standard barley cultivars. Agron. J. 83: 158-161.

Jia Q, Zhang J, Westcott S, Zhang XQ, et al. (2009). GA-20 oxidase as a candidate for the semidwarf gene sdw1/denso in barley. Funct. Integr. Genomics 9: 255-262.

Kjaer B, Jensen J and Giese H (1995). Quantitative trait loci for heading date and straw characters in barley. Genome 38: 1098-1104

Lander ES, Green P, Abrahamson J, Barlow A, et al. (1987). MAPMAKER: an interactive computer package for constructing primary genetic linkage maps of experimental and natural populations. Genomics 1: 174-181.

Li JZ, Huang XQ, Heinrichs F, Ganal MW, et al. (2005). Analysis of QTLs for yield, yield components, and malting quality in a BC3-DH population of spring barley. Theor. Appl. Genet. 110: 356-363.

Liu RH and Meng JL (2003). MapDraw: a microsoft excel macro for drawing genetic linkage maps based on given genetic linkage data. Yi. Chuan 25: 317-321.

Paterson AH, Lander ES, Hewitt JD, Peterson S, et al. (1988). Resolution of quantitative traits into Mendelian factors by using a complete linkage map of restriction fragment length polymorphisms. Nature 335: 721-726.

Pillen K, Zacharias A and Leon J (2003). Advanced backcross QTL analysis in barley (Hordeum vulgare L.). Theor. Appl. Genet. 107: 340-352. 
Ren XF, Sun DF, Guan WW and Sun GL (2010). Inheritance and identification of molecular markers associated with a novel dwarfing gene in barley. BMC Genetics 11: 89.

Saisho D, Tanno K, Chono M and Honda I (2004). Spontaneous brassinolide insensitive barley mutants 'uzu' adapted to east Asia. Breed. Sci. 54: 409-416.

Sameri M, Takeda K and Komatsuda T (2006). Quantitative trait loci controlling agronomic traits in recombinant inbred lines from a cross between oriental- and occidental-type barley cultivars. Breed. Sci. 56: 243-252.

Sameri M, Nakamura S, Nair SK, Takeda K, et al. (2009). A quantitative trait locus for reduced culm internode length in barley segregates as a Mendelian gene. Theor. Appl. Genet. 118: 643-652.

Sears RG, Kronstad WE and Metzger RJ (1981). Inheritance of dwarf and semidwarf plant height in barley. Crop Sci. 21: 828-833.

Sisler WW and Olsen PJ (1951). A study of methods of influencing lodging in barley and the effect of lodging upon yield and certain quality characteristics. Sci. Agric. 31: 177-186.

Stanca AM, Jenkins G and Hanson PR (1979). Varietal responses in spring barley to natural and artificial lodging and to a growth regulator. J. Agric. Sci. 93: 449-456.

Stein N, Herren G and Keller B (2001). A new DNA extraction method for high-throughput marker analysis in a largegenome species such as Triticum aestivum. Plant Breed. 120: 354-356.

Tar'an B, Warkentin T, Somers DJ, Miranda D, et al. (2003). Quantitative trait loci for lodging resistance, plant height and partial resistance to mycosphaerella blight in field pea (Pisum sativum L.). Theor. Appl. Genet. 107: 1482-1491.

Tavakoli H, Mohtasebi SS and Jafari A (2009). Effects of moisture content, internode position and loading rate on the bending characteristics of barley straw. Res. Agric. Eng. 55: 45-51.

Tsuchiya T (1976). Allelism testing in barley: II. Allelic relationships of three uzu genes. Crop Sci. 16: 496-499.

Varshney RK, Marcel TC, Ramsay L, Russell J, et al. (2007). A high density barley microsatellite consensus map with 775 SSR loci. Theor. Appl. Genet. 114: 1091-1103.

von Korff M, Wang H, Leon J and Pillen K (2006). AB-QTL analysis in spring barley: II. Detection of favourable exotic alleles for agronomic traits introgressed from wild barley (H. vulgare ssp. spontaneum). Theor. Appl. Genet. 112: 1221-1231.

Wang JM, Yang JM, McNeil DL and Zhou MX (2010). Identification and molecular mapping of a dwarfing gene in barley (Hordeum vulgare L.) and its correlation with other agronomic traits. Euphytica 175: 331-342.

Wang S, Basten CJ and Zeng ZB (2007). Windows QTL Cartographer 2.5. Department of Statistics, North Carolina State University, Raleigh.

Yamamoto T, Shiobara FT, Ukai Y and Sasaki T (2001). Mapping quantitative trait loci for days-to-heading, and culm, panicle and internode lengths in a $\mathrm{BC} 1 \mathrm{~F} 3$ population using an elite rice variety, Koshihikari, as the recurrent parent. Breed. Sci. 51: 63-71.

Yu GT, Horsley RD, Zhang B and Franckowiak JD (2010). A new semi-dwarfing gene identified by molecular mapping of quantitative trait loci in barley. Theor. Appl. Genet. 120: 853-861.

Zhang J (1994). Changes in plant height of varieties and analysis of dwarf sources with progress in barley breeding in China. Barley Sci. 4: 11-13.

Zhang J (2000). Inheritance of agronomic traits from the Chinese barley dwarfing gene donors 'Xiaoshan Lixiahuang' and 'Cangzhou Luodama'. Plant Breed. 119: 523-524.

Zhang J and Zhang WX (2003). Tracing sources of dwarfing genes in barley breeding in China. Euphytica 131: 285-293. 